Southern Illinois University Carbondale

OpenSIUC

Publications

Department of Zoology

$10-2011$

\title{
Structure of Parasite Component Communities of Didelphid Marsupials: Insights from a Comparative Study
}

F Agustín Jiménez

Southern Illinois University Carbondale, agustinjz@siu.edu

François Catzeflis

Universite Montpellier 2

Scott L Gardner

University of Nebraska-Lincoln

Follow this and additional works at: http://opensiuc.lib.siu.edu/zool_pubs

(C) 2011 by the American Society of Parasitologists

Published in Journal of Parasitology, Vol. 97, No. 5 (October 2011) at doi: 10.1645/GE-2711.1

Recommended Citation

Jiménez, F A., Catzeflis, François and Gardner, Scott L. "Structure of Parasite Component Communities of Didelphid Marsupials: Insights from a Comparative Study." 97, No. 5 (Oct 2011).

This Article is brought to you for free and open access by the Department of Zoology at OpenSIUC. It has been accepted for inclusion in Publications by an authorized administrator of OpenSIUC. For more information, please contact opensiuc@lib.siu.edu. 


\title{
STRUCTURE OF PARASITE COMPONENT COMMUNITIES OF DIDELPHID MARSUPIALS: INSIGHTS FROM A COMPARATIVE STUDY
}

\author{
F. Agustín Jiménez, François Catzeflis*, and Scott L. Gardner† \\ Department of Zoology, Southern Illinois University, Carbondale, Illinois 62501-6501. e-mail: agustinjz@zoology.siu.edu
}

\begin{abstract}
The parasite fauna of the gray four-eyed opossum, Philander opossum (Linnaeus, 1758), and the common opossum, Didelphis marsupialis Linnaeus, 1758, in Camp du Tigre, French Guiana, is characterized. Nine species from the gastrointestinal system were recovered from both species, which shared $80 \%$ of their parasites. The parasite fauna comprised several monoxenous species (63\%) and was dominated by Aspidodera raillieti Travassos, 1914, which exhibited high levels of prevalence and abundance in both communities. Only 2 species (Moennigia sp. and Spirura guianensis) had been recorded in other species of mammals. Both species richness and taxonomic composition at the level of component communities from this locality were compared against 11 communities present in the Virginia (Didelphis virginiana), white-bellied (Didelphis albiventris), and common opossum from Argentina, Brazil, Mexico, and the United States. Neither host phylogeny nor taxonomy accounted for statistical differences in species richness. There was no statistical difference among species richness values among the 9 localities studied. Taxonomic similarity was analyzed by means of the Jaccard's similarity index, including all, and only common species (occurring in prevalence $>10 \%$ ). The results suggest that sympatric species of marsupials share more species of parasites than parasite communities occurring in conspecific marsupials from different localities. As a consequence, taxonomic composition of these parasite communities varied depending on the locality. Probably, marsupials of the monophyletic Didelphini offer the same compatibility toward their parasites, by presenting them with similar habitats. Subtle differences in lifestyles of the marsupials may determine the chance of encounter between the symbionts and prevent some parasites from completing their life cycles. Further and more rigorous tests are necessary to determine the roles of encounter and compatibility filters, as well as the role of chance, in the structuring of parasite communities in marsupials.
\end{abstract}

A parasite community is the summation of parasite populations sharing a spatiotemporal unit (Bush et al., 1997). The structuring of a parasite community results from the interplay between evolutionary, physiologic, ecologic, geographic, and stochastic factors (Combes, 1991; Janovy et al., 1992; Choudhury and Dick, 2000; Poulin, 2007). The establishment of each parasite in its host, however, is determined by the chances of the parasite of encountering a host and by their compatibility (Combes, 1991), which determines the growth and reproduction of the parasite in the host. In addition, extrinsic factors, e.g., temperature and moisture, may determine the distribution of these parasites by favoring the survival of some, or all, the stages of the parasites in a geographic location (Pavlovsky, 1966).

Species composition and richness of parasite communities in a population of potential hosts varies across space (Dogiel, 1964; Pence, 1990; Jiménez-Ruiz et al., 2002; Poulin, 2003; González et al., 2006; Poulin and Dick, 2007). This variation has been studied at 3 levels of community organization - infracommunity, component community, and compound community-especially in freshwater and marine fish (Poulin and Dick, 2007). For mammals, the helminth component communities are variable, with taxonomic similarity negatively correlated with geographic distance (Pence, 1993; Poulin, 2003; Krasnov et al., 2005). However, Krasnov et al. (2005) found that the ectoparasite species richness was constant for taxonomically related species of hosts in sympatry. In a comparison of helminth communities of 7 species of macropodid marsupials, Beveridge et al. (1998), found a relatively high taxonomic similarity among communities occurring in sympatry, higher than similarity among communities in closely related hosts.

In vicariance biogeography, the reconstruction of area cladograms allows the interpretation of historic processes that resulted

Received 2 December 2010; revised 25 March 2011; accepted 8 April 2011.

* CNRS UMR 5554, Laboratoire Paléontologie, Case Courrier 064, Université Montpellier 2, Montpellier 34095, France.

$\dagger$ The Harold W. Manter Laboratory of Parasitology, University of Nebraska-Lincoln, Lincoln, Nebraska 68588-0547.

DOI: 10.1645/GE-2711.1 in the current distribution of species (Nelson and Platnick, 1981). Inference of relationships among parasite communities is also possible by the optimization of the distribution of parasites into the phylogeny of the hosts (Brooks and McLennan, 2002). The interpretation of the resulting reconstruction would allow inferring the factors that may have shaped the structure of these communities.

The 91 species in the monophyletic Didelphidae originated and diversified in South America (Voss and Jansa, 2009). This evolutionary event resulted in the diversification of some anatomical features that enabled marsupials to specialize in aquatic, terrestrial, scansorial, and arboreal lifestyles (Astúa, 2009). This allowed habitat segregation and the use of different dietary resources even in species occurring in sympatry (JulienLaferrière, 1991; Cáceres et al., 2002; Cunha and Vieira, 2002; Gentile et al., 2004). A very well-supported clade in the phylogeny of Didelphidae includes species of Chironectes Illiger, Lutreolina Thomas, Didelphis Linnaeus, and Philander Brisson that include the largest marsupials in the New World, commonly referred as large-sized opossums (Voss and Jansa, 2009). Some species in this clade show a wide geographic distribution (Wilson and Reeder, 2005; Gardner, 2007) and are locally common across their habitat (Fleming, 1972).

The parasite faunas of 3 species of Didelphis and 1 of Philander have been reported from 8 localities (Navone and Suriano, 1992; Alden, 1995; Cañeda-Guzmán, 1997; Ellis et al., 1999; Silva and Costa, 1999; Monet-Mendoza et al., 2005; Richardson and Campo, 2005). Up to the present time, there have been no published comparisons of the helminth faunas of marsupials from the Americas and only 1 study on 2 sympatric species of smallsized opossums, illustrating the negative correlation between parasite burdens and allelic diversity in the major histocompatibility complex (Meyer-Lucht et al., 2010).

In the present study, our 2 main goals include (1) characterization of the parasite communities found in the gray four-eyed opossum, Philander opossum (Linnaeus, 1758), and the common opossum, Didelphis marsupialis Linnaeus, 1758, from French Guiana; and (2) comparison of the structure and species richness of 13 parasite communities present in 9 different localities across 
TABLE I. Comparison of species richness in 13 communities of marsupials considering all gastrointestinal species, rare species occurring in prevalence $>10 \%$, and specific species occurring in prevalence $>10 \%$. (n) Number of opossum examined. (S) Parasite species richness.

\begin{tabular}{|c|c|c|c|c|c|}
\hline Species & Locality & $\mathrm{n}$ & S (Overall) & $\mathrm{S}(>10 \%)$ & S (Specific) \\
\hline & Minas Gerais, Brazil $\uparrow$ & 22 & 9 & 7 & 5 \\
\hline & Camp du Tigre, French Guiana & 4 & 9 & 9 & 7 \\
\hline \multirow[t]{6}{*}{ Didelphis virginiana } & Los Tuxtlas, Mexico & 10 & 13 & 9 & 7 \\
\hline & Southern Illinois, USA§ & 35 & 18 & 14 & 9 \\
\hline & Southern Illinois, USA\| & 46 & 12 & 11 & 7 \\
\hline & Colima, Mexico\# & 16 & 5 & 5 & 3 \\
\hline & Georgia, USA & 30 & 11 & 11 & 7 \\
\hline & Connecticut, USA** & 30 & 6 & 6 & 3 \\
\hline \multirow{2}{*}{ Philander opossum } & Los Tuxtlas, Mexico $\ddagger$ & 21 & 12 & 8 & 7 \\
\hline & Camp du Tigre, French Guiana & 26 & 10 & 9 & 7 \\
\hline
\end{tabular}

* Navone and Suriano, 1992

+ Silva and Costa, 1999.

+ Cañeda-Guzmán, 1997.

$\S$ Cordell, 1974.

॥Alden, 1995.

\# Monet-Mendoza et al., 2005.

- Ellis et al., 1999.

** Richardson and Campo, 2005

the Americas. The aim of the latter goal is to contrast the role of geographic locality versus marsupial phylogeny on the structure of parasite communities. By comparing parasite communities that occur in sympatry and in phylogenetically related hosts, we may determine whether parasite species richness is a variable or a constant attribute of a host taxon, i.e., species name, and whether taxonomic similarity is greater among parasite communities occurring in phylogenetically related hosts or among parasite communities occurring in the same locality. As seen in studies comparing parasite communities of closely related hosts (Beveridge et al., 1998; Jiménez-Ruiz et al., 2002), we anticipate that sympatric species of marsupials would share a large number of species of parasites because of the similarity of lifestyles, food items, and their exposure to the same pool of parasites.

\section{MATERIALS AND METHODS}

Specimens were collected 1-15 March 2001 in old mature secondary forests within the same locality (Camp du Tigre, near Cayenne, French Guiana; $\left.04^{\circ} 54^{\prime} 30^{\prime \prime} \mathrm{N}, 52^{\circ} 18^{\prime} 30^{\prime \prime} \mathrm{W}\right)$. Preserved specimens of hosts $(P$. opossum) were deposited at the Museum National Histoire Naturelle, Paris, France (catalog numbers 2001-1346-1350, 2001-1352 and -1353, and 2001-1374-1376), and at the University of Montpellier, Montpellier, France (collection of F. Catzeflis under field numbers V-1241, V-1246-1248, V1254, V-1262, V-1298, V-1314, V-1315, V-1330, V-1331, V-1337, V-1344, V1347, V-1348, and V-1359-1362). The gastrointestinal contents were preserved in $4 \%$ formalin and transported to the laboratory to be examined for helminths. Preservation, staining, clearing, and mounting of parasites followed Pritchard and Kruse (1982). Vouchers for this study were deposited in the HWML and the Collection Parasitologique du Museum d'Histoire Naturelle (Paris, France). Definitions of prevalence, abundance, mean intensity, and other ecologic descriptors follow Bush et al. (1997).

Helminthologic surveys with sample sizes of at least 10 individuals were used in the comparisons of parasite communities. These included Didelphis albiventris, Didelphis virginiana, D. marsupialis, and P. opossum from 8 localities across the distribution of these species (Cordell, 1974; Navone and Suriano, 1992; Alden, 1995; Cañeda-Guzmán, 1997; Ellis et al., 1999; Silva and Costa, 1999; Monet-Mendoza et al., 2005; Richardson and Campo, 2005). The parasite community of each marsupial species per locality (component community) was considered a community. Based on the difference in species richness and species composition an exception was made for 2 surveys separated by $20 \mathrm{yr}(D$. virginiana from southern Illinois in the United States; Table I).

The presence of parasites in 4 species of large sized marsupials collected across 9 different localities was tabulated into a binary table (Table II). Qualitative taxonomic similarity of these parasite communities was measured by means of the Jaccard's similarity index as implemented in SAS (SAS Institute Inc., 2009). To evaluate the effect of phylogeny on the taxonomic similarity of the parasite communities, the matrix was analyzed in PAUP* b4.10 (Swofford, 2003), enforcing the phylogeny of the hosts. The phylogenetic tree $(((D$. albiventer: $0.0023, D$. marsupialis: 0.0026$)$ : 0.0012 , D. virginiana: 0.0061): 0.0011, P. opossum: 0.0053) (Voss and Jansa, 2009), was used as a constraint for the phylogenetic relationships among the species. This constraint also served to test for correlations between parasite species richness (log-transformed values) and the 4 species of marsupials by means of the independent contrast approach (Felsenstein, 1985) as implemented in PHYLIP version 3.69 (Felsenstein, 2009).

Species richness of parasites was compared among the 13 different communities sampled. First, the effect of host phylogeny on values of species richness was examined by linear regression under an independent contrast frame (Felsenstein, 1985). This allowed testing the hypothesis that parasite species richness is an attribute of each of the 4 species of marsupials studied. Second, the effect of each of the 9 localities on the species richness was assessed using Welch's analysis of variance (Welch, 1947); this test was chosen because of the unequal variances among the samples and different sample sizes of both localities and species studied. This approach treats each of the variances separately, by reducing the impact of heteroscedasticity on the analysis

All analyses and tests were performed on 2 different treatments to the data set; the first treatment included all species of parasites in the communities. For the second treatment, rare species occurring in low prevalence $(<10 \%)$ were removed (Table III). This resulted in the exclusion of 0 to 5 species of helminths per component community.

\section{RESULTS}

In total, 10 species of parasites was recovered from the digestive system of the gray four-eyed opossums collected in Camp du Tigre. From that total, 5 species were collected from the small intestine, 3 from the cecum and large intestine, and 1 from the stomach. An additional species (Cherylia guyanensis Bain, Petit, Jacquet-Vallet and Houin, 1983) was recovered from the body 
cavity. All gastrointestinal parasites, except Moennigia sp., were found with prevalence $>25 \%$. Travassostrongylus paraquintus Durette-Desset, 1974 reached maximum values of prevalence and mean abundance, whereas $A$. raillieti exhibited the highest mean intensity (Table IV). The parasite fauna of $D$. marsupialis in the same locality also includes 9 species, with $A$. raillieti showing the highest values of both prevalence and mean intensity. The tapeworm Mathevotaenia bivittata (Janicki, 1904) was collected from the common opossum exclusively, whereas Moennigia sp. and Oligacanthorhynchus microcephala (Rudolphi, 1819) were only recorded in the gray four-eyed opossum.

In the comparison of 13 parasite communities present in largesized opossums, the minimum value for species richness was 5 and the maximum was 18 , with the maximum value found in southern Illinois (Table I). The minimum values of species richness corresponded with D. albiventris in Santiago del Estero, Argentina, and D. virginiana in Colima, Mexico. After removing rare species from the analysis, species richness at Santiago del Estero and southern Illinois dropped to 3 and 14, respectively. The last column in Table I shows the parasite species richness for only marsupial-specific parasites.

The results show no correlation between parasite species richness and host species $(F=0.44 ; 3,2.78 \mathrm{df} ; P=0.74)$. No correlation was detected between parasite species richness and locality $(F=4.81 ; 2.0,1.96 \mathrm{df} ; P=0.18)$. Parasite species richness among localities shows no difference when only communities occurring in D. virginiana were compared $\left(\chi^{2}=5.54\right.$, df $5, P=$ $0.35)$. When all species of parasites were considered, no significant correlation was found between richness and host sample size among all 13 communities $(r=0.11, P=0.73 ; \mathrm{n}=13)$. This pattern persisted when statistical tests were framed onto an independent contrast approach $(\mathrm{H}=0.34$, df $3, P=0.95)$. Because $D$. virginiana included the largest sample size (7 parasite communities collected in 6 localities), we tested for significant correlation between sample size per locality and parasite species richness. No correlation was found among these communities for these 2 variables ( $r=0.39, P=0.38 ; \mathrm{n}=7)$, which suggested that sample size had no effect on parasite species richness.

The comparisons of parasite communities across geographic localities resulted in low qualitative taxonomic similarity for all samples. Only parasite communities from sympatric hosts showed similarity $>60 \%$, irrespective of the host species. These include communities present in Camp du Tigre; Los Tuxtlas, Mexico; and southern Illinois (Fig. 1). The cladogram resulted in 2 trees, 62 steps long, with a rescaled consistency index of $56 \%$. These trees group sympatric communities irrespective of the phylogenetic affinities of their hosts (data not shown). The analysis of the dataset enforcing the phylogenetic relationships among the species of hosts resulted in 9 longer trees ( 89 steps), with a rescaled consistency index of $20 \%$.

When rare species of parasites (present in $<10 \%$ of the hosts) were excluded from the analyses, richness was independent of the host taxon $(F=0.82 ; 2.0,2.39 \mathrm{df} ; F=0.54)$, and no significant differences were found among localities $(F=0.37 ; 1,1.2534 \mathrm{df}$; $F=0.37$ ). In addition, no significant correlation was found between host sample size and parasite species richness either globally $(r=0.13, P=0.66 ; \mathrm{n}=13$ ) or among communities present exclusively in $D$. virginiana $(r=0.67, \mathrm{n}=7, p=0.1)$. The pattern persisted for the former group when the analysis was framed into an independent contrast analysis $(\mathrm{H}=0.92,3 \mathrm{df}, P=0.82)$.
High taxonomic similarity among parasite communities occurring in sympatric hosts persisted even when rare species were excluded (data not shown). The only exception was found in Los Tuxtlas. In this locality, the similarity among communities occurring in $P$. opossum and the 2 species of Didelphis dropped to $<60 \%$. Low levels of similarity $(<60 \%)$, characterized $92 \%$ of the pairs compared, including $17 \%$ of pairs that showed values of similarity $=0$. The grouping of the component communities based on their similarity values is shown in Figure 2. The 4 resulting cladograms for this data set were 52 steps long with a rescaled consistency index of $56 \%$. Enforcing the monophyly of the hosts on the relationships among parasite communities resulted in a tree 19 steps longer.

Finally, the analysis of taxon-specific species of parasites occurring with a prevalence of $<10 \%$ resulted in no significant correlation among log transformed values of species richness and species of host $(F=2.44 ; 2.0,2.24 \mathrm{df} ; P=0.27)$.

\section{DISCUSSION}

\section{Parasites of opossums in French Guiana}

The parasite communities of both $P$. opossum and $D$. marsupialis collected in French Guiana seemed to be dominated by parasites with direct patterns of transmission. This is indicated by the highest values of prevalence and mean intensity of $T$. paraquintus, $V$. viannai, Travassostrongylus reesali, and $A$. raillieti. From this locality, 5 of the species collected are indirectly transmitted. These species occurred in low prevalence, with relatively low mean intensities. This may be the result of either low prevalence of these parasites in their intermediate hosts or the wide spectrum of food items used by these marsupials (Carvalho et al., 2005). Both would reduce their chances of ingesting infected intermediate hosts. It has been shown that a higher diversity of prey items may reduce the chances of the definitive host becoming infected by parasites with a high degree of specialization in their use of intermediate hosts (Combes, 1991). We lack the empirical evidence to test and compare these 2 hypotheses.

The communities present in both species of marsupials shared a great number of parasite species, most of which are specialists to marsupials (64\% for P. opossum and $78 \%$ for D. marsupialis). These results are congruent with the generalist lifestyles and, to a lesser extent, the overlapping diets of both species of opossums (Julien-Laferrière and Atramentowicz, 1990). Both marsupial species may be equally exposed to the parasites present in that locality and may be similarly compatible with them, because of the relatedness of the 2 marsupial species (Combes, 1991). The inclusion of other species of this monophyletic tribe in the locality (Chironectes minimus and Didelphis imperfecta) and the contrast with species from other clades in the phylogeny of marsupials, i.e., species of Marmosa, Marmosops, Metachirus, and Monodelphis may help in testing this hypothesis.

The values of parasite species richness were similar between both communities. Those values were 10 in the gray four-eyed opossum and 9 for communities in the common opossum. However, those values dropped to 9 in both cases when rare species were removed from the comparisons and to 7 when only specialists remained. These differences are caused by 4 species (Mathevotaenia bivittata, Moennigia sp., O. microcephala, and S. guianensis). 
TABLE II. Distribution of 46 species of parasites in 13 parasite communities across the Americas. All species of enteric helminths were included. Number of opossums examined (n) and parasite species richness per component community (S) are indicated. Helminths are labeled as having indirect (I) or direct (D) patterns of transmission and as being specific (P) or generalist $(\mathrm{G})$ to didelphid marsupials.

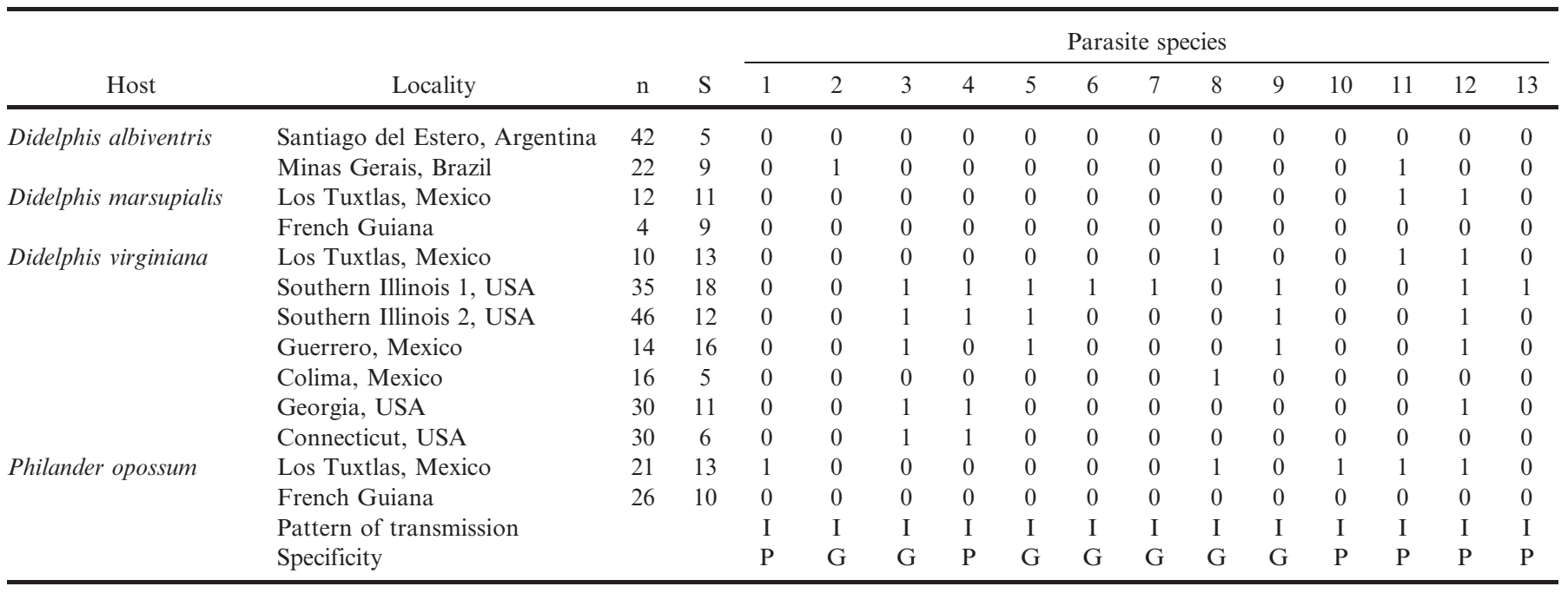

List of parasite species: 1, Amphimerus cauditestis; 2, Brachylaima migrans; 3, Brachylaima virginianum; 4, Diplostomum variabile; 5, Echinoparyphium contiguum; 6 , Fibricola crater; 7, Fibricola lucidus; 8, Paragonimus mexicanus; 9, Paragonimus westermani; 10, Philandrophilus magnicirrus; 11, Rhopalias coronatus; 12, Rhopalias macracanthus; 13, Linstowia sp.; 14, Mathovataenia argentinensis; 15, Mathevotaenia bivittata; 16, Mesocestoides sp.; 17, Thaumasioscolez didelphis; 18, Capillaria aerophila; 19, Capillaria eberthi; 20, Capillaria longicauda; 21, Cruzia americana; 22, Cruzia tentaculata; 23, Didelphonema sp.; 24, Gnathostoma turgidum; 25, Gongylonema sp.; 26, Gongylonema mexicanum; 27, Longistriata didelphis; 28, Aspidodera raillieti; 29, Moennigia sp.; 30, Physaloptera turgida; 31, Pterygodermatites kozeki; 32, Spirura guianensis; 33, Travassostrongylus orloffi; 34, Travassostrongylus paraquintus; 35, Trichuris didelphis; 36, Trichuris minuta; 37, Trichuris reesali; 38, Viannaia didelphis; 39, Viannaia hamata; 40, Viannaia sp.; 41, Viannaia viannaia; 42, Oligacanthorhynchus tortuosa; 43, Oligacanthorhynchus microcephala; 44, Oncicola campalunata; 45, Oncicola luhei; and 46, Porrorhynchus nickoli.

\section{Species richness across hosts and localities}

Parasite species richness was not statistically different across the geographic distribution of a single species of marsupial, as seen in the parasites of $D$. virginiana across 7 localities. The overall parasite species richness for these communities fluctuated between 5 and 18. Even when only host-specific species of parasites were considered, the values of species richness fluctuated between 1 and 9 (Table I). In contrast, the pairs of parasite communities present in $D$. marsupialis and $P$. opossum had very similar values of species richness, especially when only specific

TABLE III. Distribution of 38 species of enteric parasites occurring in prevalence $>10 \%$ in 13 parasite communities across the Americas. Number of opossums examined (n) and parasite species richness per component community (S) are indicated. Helminths are labeled as having indirect (I) or direct (D) patterns of transmission and as being specific $(\mathrm{P})$ or generalist $(\mathrm{G})$ to didelphid marsupials.

\begin{tabular}{|c|c|c|c|c|c|c|c|c|c|c|c|c|c|}
\hline Host & Locality & $\mathrm{n}$ & $\mathrm{S}$ & \multicolumn{10}{|c|}{ Parasite species } \\
\hline Didelphis albiventris & Santiago del Estero, Argentina & 42 & 3 & 0 & 0 & 0 & 0 & 0 & 0 & 0 & 0 & 1 & 0 \\
\hline \multirow{2}{*}{ Didelphis marsupialis } & Los Tuxtlas, Mexico & 12 & 9 & 0 & 0 & 0 & 0 & 0 & 0 & 1 & 1 & 0 & 0 \\
\hline & French Guiana & 4 & 9 & 0 & 0 & 0 & 0 & 0 & 0 & 0 & 0 & 0 & 1 \\
\hline \multirow[t]{5}{*}{ Didelphis virginiana } & Los Tuxtlas, Mexico & 10 & 9 & 0 & 0 & 0 & 0 & 0 & 0 & 1 & 1 & 0 & 0 \\
\hline & Guerrero, Mexico & 14 & 5 & 1 & 0 & 0 & 0 & 0 & 0 & 0 & 0 & 0 & 0 \\
\hline & Colima, Mexico & 16 & 5 & 0 & 0 & 0 & 0 & 1 & 0 & 0 & 0 & 0 & 0 \\
\hline & Georgia, USA & 30 & 11 & 1 & 1 & 0 & 0 & 0 & 0 & 0 & 1 & 0 & 0 \\
\hline & Connecticut, USA & 30 & 6 & 1 & 1 & 0 & 0 & 0 & 0 & 0 & 0 & 0 & 0 \\
\hline \multirow{2}{*}{ Philander opossum } & Los Tuxtlas, Mexico & 21 & 8 & 0 & 0 & 0 & 0 & 1 & 0 & 1 & 1 & 0 & 0 \\
\hline & French Guiana & 26 & 9 & 0 & 0 & 0 & 0 & 0 & 0 & 0 & 0 & 0 & 0 \\
\hline
\end{tabular}

List of parasite species: 1, Brachylaima virginianum; 2, Diplostomum variabile; 3, Fibricola crater; 4, Fibricola lucidus; 5 , Paragonimus mexicanus; 6 , Paragonimus westermani; 7. Rhopalias coronatus; 8, Rhopalias macracanthus; 9, Mathovataenia argentinensis; 10, Mathevotaenia bivittata; 11, Mesocestoides sp.; 12, Thaumasioscolez didelphis; 13, Capillaria aerophila; 14, Capillaria eberthi; 15, Capillaria longicauda; 16, Cruzia americana; 17, Cruzia tentaculata; 18, Didelphonema sp.; 19, Gnathostoma turgidum; 20, Gongylonema mexicanum; 21, Longistriata didelphis; 22, Aspidodera raillieti; 23, Physaloptera turgida; 24, Spirura guianensis; 25, Travassostrongylus orloffi; 26, Travassostrongylus paraquintus; 27, Trichuris didelphis; 28, Trichuris minuta; 29, Trichuris reesali; 30, Viannaia didelphis; 31, Viannaia hamata; 32, Viannaia sp.; 33, Viannaia viannaia; 34, Oligacanthorhynchus tortuosa; 35, Oligacanthorhynchus microcephala; 36, Oncicola campalunata; 37, Oncicola luhei; and 38, Porrorhynchus nickoli. 
TABLE II. Extended.

\begin{tabular}{|c|c|c|c|c|c|c|c|c|c|c|c|c|c|c|c|c|c|c|c|c|c|c|c|c|c|c|c|c|c|c|c|c|}
\hline \multicolumn{33}{|c|}{ Parasite species } \\
\hline 1 & 0 & 0 & 0 & 0 & 0 & 0 & 0 & 0 & 0 & 0 & 0 & 0 & 0 & 1 & 0 & 1 & 1 & 0 & 0 & 0 & 0 & 0 & 0 & 0 & 0 & 0 & 0 & 0 & 1 & 0 & 0 & 0 \\
\hline 0 & 0 & 0 & 1 & 0 & 0 & 0 & 0 & 1 & 1 & 0 & 0 & 1 & 0 & 0 & 0 & 1 & 0 & 0 & 0 & 0 & 1 & 0 & 0 & 0 & 0 & 1 & 0 & 1 & 0 & 0 & 0 & 1 \\
\hline 0 & 1 & 0 & 0 & 0 & 1 & 0 & 0 & 1 & 0 & 0 & 0 & 0 & 0 & 1 & 0 & 0 & 0 & 1 & 0 & 1 & 0 & 0 & 1 & 0 & 0 & 0 & 1 & 0 & 0 & 1 & 0 & 0 \\
\hline 0 & 0 & 0 & 1 & 0 & 0 & 0 & 0 & 1 & 1 & 0 & 0 & 1 & 0 & 0 & 0 & 1 & 0 & 0 & 0 & 0 & 1 & 0 & 0 & 0 & 0 & 1 & 0 & 1 & 0 & 0 & 1 & 1 \\
\hline 0 & 0 & 1 & 0 & 1 & 0 & 1 & 1 & 1 & 1 & 1 & 0 & 0 & 1 & 0 & 0 & 1 & 0 & 0 & 0 & 0 & 1 & 0 & 0 & 0 & 0 & 1 & 1 & 0 & 0 & 0 & 0 & 0 \\
\hline 0 & 0 & 0 & 0 & 0 & 0 & 0 & 1 & 1 & 0 & 0 & 0 & 0 & 0 & 0 & 0 & 1 & 0 & 0 & 0 & 0 & 0 & 0 & 0 & 1 & 0 & 0 & 0 & 0 & 0 & 0 & 0 & 0 \\
\hline 0 & 0 & 1 & 0 & 0 & 0 & 0 & 1 & 0 & 0 & 1 & 0 & 0 & 1 & 0 & 0 & 1 & 0 & 0 & 0 & 0 & 1 & 0 & 0 & 0 & 1 & 0 & 0 & 1 & 0 & 0 & 0 & 0 \\
\hline 0 & 0 & 1 & 0 & 0 & 0 & 1 & 1 & 0 & 0 & 0 & 0 & 0 & 0 & 0 & 0 & 1 & 0 & 0 & 0 & 0 & 0 & 0 & 0 & 0 & 0 & 0 & 0 & 0 & 0 & 0 & 0 & 0 \\
\hline 0 & 0 & 0 & 1 & 0 & 0 & 0 & 0 & 1 & 0 & 0 & 0 & 1 & 0 & 0 & 0 & 1 & 0 & 0 & 0 & 0 & 1 & 0 & 0 & 0 & 0 & 1 & 0 & 1 & 0 & 0 & 0 & 1 \\
\hline 0 & 0 & 0 & 0 & 0 & 1 & 0 & 0 & 1 & 0 & 0 & 0 & 0 & 0 & 1 & 1 & $?$ & 0 & 1 & 0 & 1 & 0 & 0 & 1 & 0 & 0 & 0 & 1 & 0 & 1 & 1 & 0 & 0 \\
\hline
\end{tabular}

species of parasites were considered. Similar results were obtained when rare species were excluded from the comparisons.

In Los Tuxtlas, the 3 sympatric species of opossums, which constitute 3 parasite communities, show similar values of parasite species richness (Table I). In this locality, a set of parasites with indirect patterns of transmission appeared in different frequencies in the sympatric marsupials. This set may be divided into specific (Thaumasioscolex didelphidis and Porrorchis nickoli) and nonspecific species (Paragonimus mexicanus, Turgida turgida, and
Oligacanthorhynchus tortuosa). All of these species use an intermediate host to complete the transmission to their final host. Also, with the exception of $P$. mexicanus, all parasite species showed low prevalence in the gray four-eyed opossum and relative high values of prevalence in both species of Didelphis. The wider spectrum of food resources used by both species of Didelphis relative to $P$. opossum, which forages on aquatic arthropods, may help explaining this difference (Cañeda-Guzmán, 1997). Both the common and the Virginia opossum would

TABLE III. Extended.

\begin{tabular}{|c|c|c|c|c|c|c|c|c|c|c|c|c|c|c|c|c|c|c|c|c|c|c|c|c|c|c|c|}
\hline \multicolumn{28}{|c|}{ Parasite species } \\
\hline 11 & 12 & 13 & 14 & 15 & 16 & 17 & 18 & 19 & 20 & 21 & 22 & 23 & 24 & 25 & 26 & 27 & 28 & 29 & 30 & 31 & 32 & 33 & 34 & 35 & 36 & 37 & 38 \\
\hline 0 & 0 & 0 & 0 & 0 & 0 & 0 & 0 & 0 & 0 & 0 & 1 & 1 & 0 & 0 & 0 & 0 & 0 & 0 & 0 & 0 & 0 & 0 & 0 & 0 & 0 & 0 & 0 \\
\hline 0 & 0 & 0 & 0 & 0 & 0 & 1 & 0 & 0 & 0 & 0 & 1 & 1 & 0 & 1 & 0 & 1 & 0 & 0 & 0 & 1 & 0 & 0 & 0 & 0 & 0 & 0 & 0 \\
\hline 0 & 1 & 0 & 0 & 0 & 0 & 1 & 0 & 0 & 1 & 0 & 0 & 1 & 0 & 0 & 0 & 0 & 0 & 0 & 0 & 0 & 1 & 0 & 1 & 0 & 0 & 0 & 1 \\
\hline 0 & 0 & 0 & 1 & 0 & 0 & 1 & 0 & 0 & 0 & 0 & 1 & 0 & 1 & 0 & 1 & 0 & 0 & 1 & 0 & 0 & 0 & 1 & 0 & 0 & 1 & 0 & 0 \\
\hline 0 & 1 & 0 & 0 & 0 & 0 & 0 & 0 & 0 & 1 & 0 & 0 & 1 & 0 & 0 & 0 & 1 & 0 & 0 & 0 & 0 & 1 & 0 & 1 & 0 & 0 & 1 & 0 \\
\hline 1 & 0 & 1 & 0 & 1 & 1 & 0 & 0 & 0 & 0 & 1 & 0 & 1 & 0 & 0 & 0 & 0 & 1 & 0 & 0 & 1 & 0 & 0 & 1 & 0 & 0 & 0 & 0 \\
\hline 1 & 0 & 1 & 0 & 1 & 1 & 0 & 0 & 0 & 0 & 1 & 0 & 1 & 0 & 0 & 0 & 0 & 0 & 0 & 0 & 0 & 0 & 0 & 1 & 0 & 0 & 0 & 0 \\
\hline 0 & 0 & 0 & 0 & 0 & 1 & 0 & 1 & 0 & 0 & 0 & 0 & 1 & 0 & 0 & 0 & 0 & 0 & 0 & 0 & 0 & 0 & 1 & 0 & 0 & 0 & 0 & 0 \\
\hline 0 & 0 & 0 & 0 & 0 & 1 & 1 & 0 & 0 & 0 & 0 & 0 & 1 & 0 & 0 & 0 & 0 & 0 & 0 & 1 & 0 & 0 & 0 & 0 & 0 & 0 & 0 & 0 \\
\hline 1 & 0 & 0 & 0 & 0 & 1 & 0 & 0 & 1 & 0 & 1 & 0 & 1 & 0 & 0 & 0 & 1 & 0 & 0 & 0 & 1 & 0 & 0 & 1 & 0 & 0 & 0 & 0 \\
\hline 1 & 0 & 0 & 0 & 1 & 1 & 0 & 0 & 0 & 0 & 0 & 0 & 1 & 0 & 0 & 0 & 0 & 0 & 0 & 0 & 0 & 0 & 0 & 0 & 0 & 0 & 0 & 0 \\
\hline 0 & 0 & 0 & 0 & 0 & 0 & 1 & 0 & 0 & 1 & 0 & 0 & 0 & 0 & 0 & 0 & 1 & 0 & 0 & 0 & 0 & 1 & 0 & 0 & 0 & 0 & 0 & 1 \\
\hline 0 & 0 & 0 & 1 & 0 & 0 & 1 & 0 & 0 & 0 & 0 & 1 & 0 & 1 & 0 & 1 & 0 & 0 & 1 & 0 & 0 & 0 & 1 & 0 & 1 & 1 & 0 & 0 \\
\hline I & I & $\mathrm{D}$ & $\mathrm{D}$ & $\mathrm{D}$ & $\mathrm{D}$ & $\mathrm{D}$ & I & I & I & $\mathrm{D}$ & D & I & I & $\mathrm{D}$ & $\mathrm{D}$ & $\mathrm{D}$ & $\mathrm{D}$ & $\mathrm{D}$ & $\mathrm{D}$ & $\mathrm{D}$ & $\mathrm{D}$ & $\mathrm{D}$ & I & I & I & I & I \\
\hline $\mathrm{G}$ & $\mathrm{P}$ & $\mathrm{P}$ & $\mathrm{P}$ & $\mathrm{P}$ & $P$ & $\mathrm{P}$ & $\mathrm{P}$ & $\mathrm{G}$ & $\mathrm{P}$ & $\mathrm{P}$ & $\mathrm{G}$ & $\mathrm{G}$ & $\mathrm{G}$ & $\mathrm{P}$ & $\mathrm{P}$ & $\mathrm{P}$ & $\mathrm{P}$ & $\mathrm{P}$ & $\mathrm{P}$ & $\mathrm{P}$ & $\mathrm{P}$ & $\mathrm{P}$ & $\mathrm{P}$ & $\mathrm{P}$ & $\mathrm{P}$ & $\mathrm{G}$ & $\mathrm{P}$ \\
\hline
\end{tabular}


TABLE IV. Characterization of infection of gray four-eyed opossum, Philander opossum $(\mathrm{n}=26)$ and common opossum, Didelphis marsupialis $(\mathrm{n}=4)$ in Camp du Tigre, District of Cayenne, French Guiana. \pm SD follows mean intensity and mean abundance.

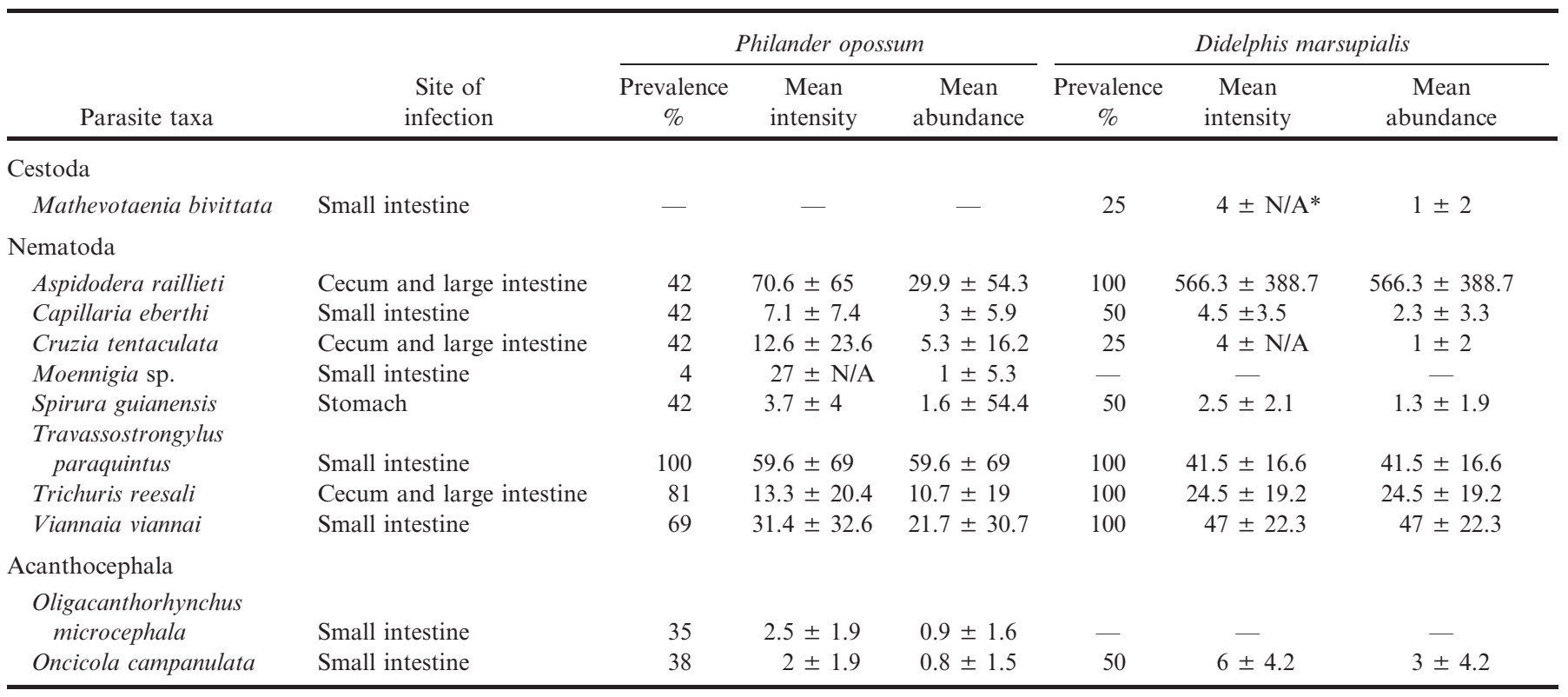

* N/A, not applicable

be exposed to intermediate hosts carrying the infective stages of those species, via frequent ingestion of terrestrial invertebrates.

\section{Species composition}

Most of the parasite species present in these communities were specialists; however, some of the communities sampled close to the edge of the host distribution showed a high proportion of generalist species. Eighty per cent of the parasite species in $D$. albiventris in Santiago del Estero, Argentina, were generalists (Navone and Suriano, 1992). Overall, the parasite communities present in D. virginiana in southern Illinois seem to be richer than all the others; yet, $50 \%$ of those species are generalists and usually infect other species of mammals (Anderson, 2000). A similar trend was observed in the community present in the Virginia opossum from Connecticut. The phenomenon of loss of diversity, i.e., species richness, toward the extremes of the host distribution of the host species has been observed in other groups of

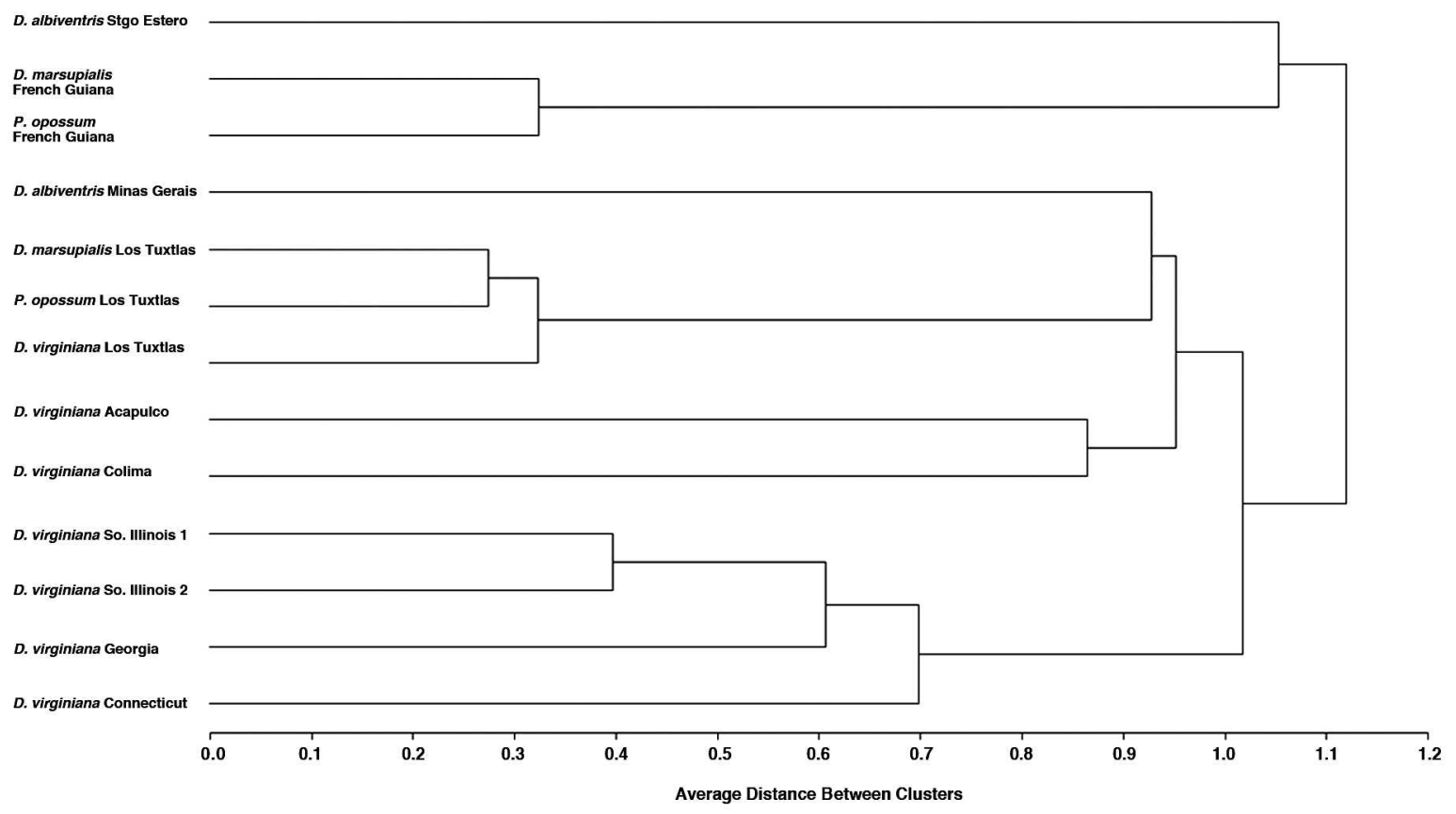

FIGURE 1. Similarity based on Jaccard's similarity index among parasite communities of 4 species of didelphid marsupials across 9 different localities. All the species of parasites present in the digestive tract have been included in the analysis. 


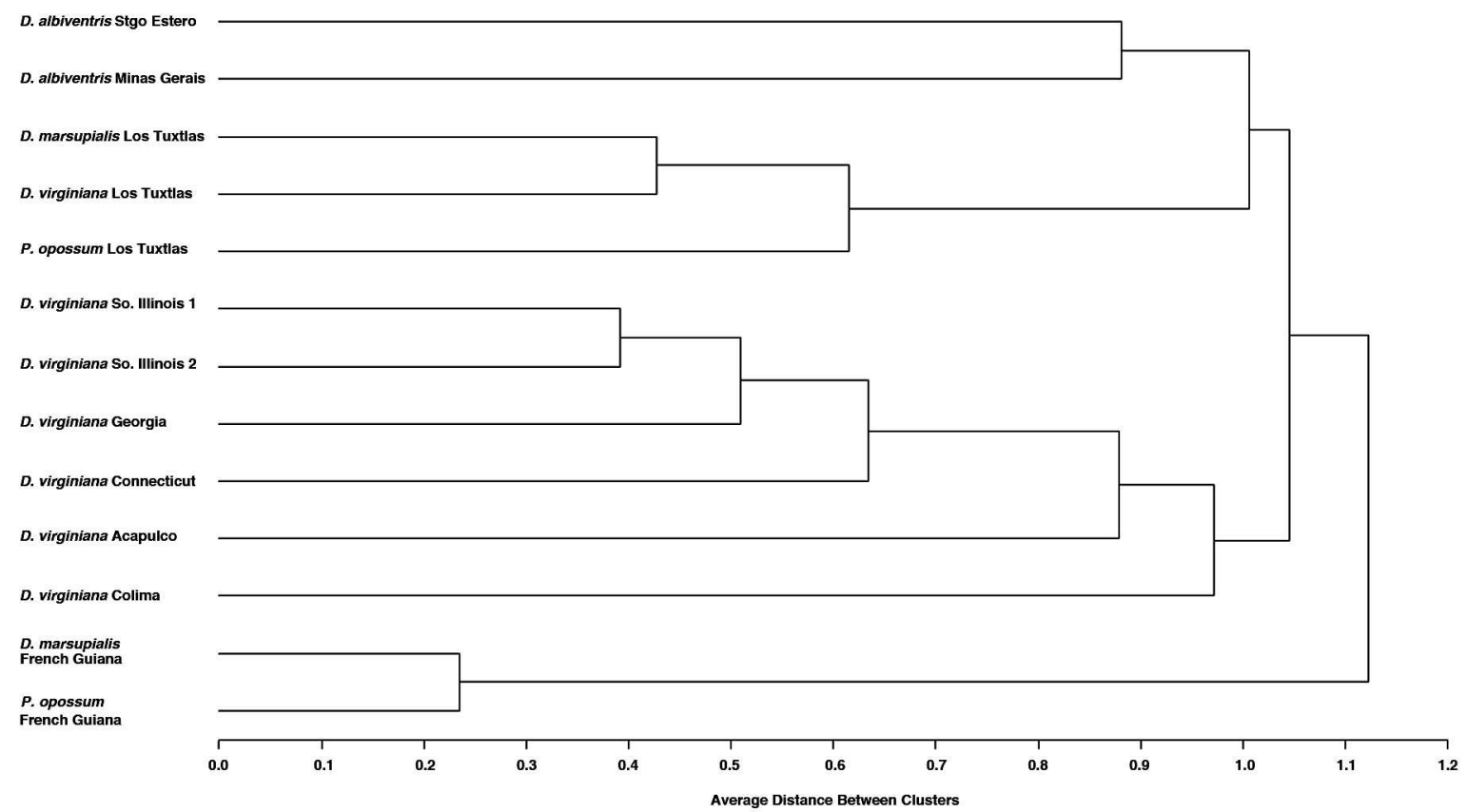

FIGURE 2. Similarity based on Jaccard's similarity index among parasite communities of 4 species of didelphid marsupials across 9 different localities. Only species of endoparasites present with a prevalence $>10 \%$ were included in the analysis.

vertebrates (Dogiel, 1964; Poulin and Dick, 2007). Although this phenomenon seems to occur here, additional analyses are necessary to test it.

One could expect that the parasites of primarily tropical marsupials are not adapted to the seasonal changes occurring in Boreal and Austral temperate localities of the New World. This could be particularly important for the geohelminths, species with direct patterns of transmission in which survival of at least 1 stage of their life cycles (usually the eggs) depends on the external environment. An example includes $A$. raillieti and Viannaia sp., 2 common parasites of the opossums across the Neotropics, but they also are present in southern Illinois. These species were collected in low prevalence in this locality, even though they may be quite prevalent in other geographic localities through the range of their host(s). As is the case for other heterakoids, the embryonated eggs of $A$. raillieti are voided with the feces and remain in the soil until ingested by the host. However, to remain infective, they require relatively constant temperature and humidity (Anderson, 2000). A direct consequence of this requirement would be the disappearance of the parasites from localities where seasonality would induce drastic changes in both temperature and humidity. This would explain the changes in species composition due to the loss of $A$. raillieti, Viannaia sp., and Linstowia sp. in southern Illinois in 2 surveys separated by 2 decades (Cordell, 1974; Alden, 1995).

\section{Taxonomic similarity}

Parasite communities occurring in the same locality showed higher levels of taxonomic similarity than communities of conspecific species of marsupials. This was the case for communities present in French Guiana, Los Tuxtlas, and the 2 communities of the Virginia opossum from southern Illinois. This pattern is concordant with the 1 found in helminth communities of macropodids (Beveridge et al., 1998), in that taxonomic similarity is higher among communities in hosts occurring in sympatry.

Only parasite communities from the United States formed a cluster with biogeographic meaning in that they belong to the Nearctic region (Fig. 1). The values of similarity among these communities seemed to be higher than the values of similarity for communities present in the Neotropical region, even when communities in the latter region were geographically closer. The communities present in marsupials from Mexico illustrate this point, suggesting that linear/geographic distance does not seem to play a preponderant role in the similarity among these communities. The 3 localities in the United States are separated by 940 to $1,400 \mathrm{~km}$ and they share at least $50 \%$ of species of parasites. In contrast, communities analyzed in Mexico share $<25 \%$ of parasite species even though they are separated by 498 to $922 \mathrm{~km}$. Geographic barriers and drastic changes in the biomes may provide a better explanation for these differences.

Similarity among communities always decreased when rare species were removed from the analysis. In Los Tuxtlas, the similarity between communities in $P$. opossum compared with $D$. marsupialis and D. virginiana dropped to approximately 50\% (55 and $42 \%$, respectively). The different diet composition of the 2 species of Didelphis relative to the gray four-eyed opossum may account for this difference (McManus, 1974; Castro-Arellano et al., 2000; Astúa, 2009).

Applying constraints by enforcing phylogenetic relationships of the marsupials on the distribution of species of parasites resulted in trees 27 and 19 steps longer than in the nonconstrained trees. These results suggest that many parasites are not species specific (to host) and that they are compatible with any of the species of sympatric marsupials studied. The detection of some species that are not known to occur in other 
mammals suggests that this compatibility may be exclusive to this group of marsupials, possibly in a form of specificity of the parasites towards members of a clade (Choudhury and Dick, 2001). This hypothesis could be tested by including sympatric species of mouse opossums in the analysis, because they belong to different clades in the phylogeny of the marsupials (Voss and Jansa, 2009).

\section{General conclusions}

Our results suggest the following: (1) species richness is a variable attribute for any given species of host, (2) species composition is variable across localities, and (3) sympatric species of marsupials share more species of parasites than sister species do across the localities compared. As a consequence, the comparison among localities did not allow us to detect any statistically significant differences among species richness, species of hosts, and locality. This suggests that the parasites present in 1 locality are capable of infecting sympatric species of marsupials with similar ecology.

The study of parasite communities occurring in sympatric and closely related species of marsupials over geographic space is an excellent system with which to test interactions among the filters that allow species, populations, and perhaps individuals of mammals or other vertebrates to become infected with various parasites. The study of the parasites comprising the communities in both species of hosts and in geographic areas would help in detecting trends in modes of infection and in compatibility among symbionts. In our study, it seems that marsupials of the monophyletic Didelphini offer the same resources to their parasites by sharing similar morphologic, behavioral, and physiologic traits. Mostly, the marsupials would acquire parasites of the same set of species present in a given area, resulting in high taxonomic similarity among sympatric communities. The subtle differences in lifestyles of the marsupials may determine the chance of encounter between the symbionts and prevent some parasites from completing their life cycles. Further and more rigorous tests to determine the role of encounter and compatibility filters, as well as the role of chance in the structuring of parasite communities in marsupials, are necessary.

\section{ACKNOWLEDGMENTS}

We thank Jacques Gardon and Jean-Francois Mauffrey for invaluable help for collecting opossums at Camp du Tigre, Cayenne. Our appreciation is extended to Beth Byles, Sean Elliot, and Brittany Schlake for assistance in the parasitologic examinations and to Dr. Laura Campbell for reading an earlier draft of this manuscript. Fieldwork in French Guiana was partially funded by Institut Pasteur de Cayenne. Support was provided to F.A.J. by CONACyT-Mexico. This study was supported, in part, by faculty seed grants ORDA-SIU to F.A.J. and NSF grants DEB-0717214, BSR-9024816, DEB-0097019 DBI-0646356, and DBI-0097019 to S.L.G

\section{LITERATURE CITED}

Alden, K. J. 1995. Helminths of the opossum Didelphis virginiana, in southern Illinois, with a compilation of all helminths reported from this host in North America. Journal of the Helminthological Society of Washington 62: 197-208.

Anderson, R. C. 2000. Nematode parasites of vertebrates. Their development and transmission, 2nd ed. CAB International, Farnham Royal, U.K., 650 p.
AstúA, D. 2009. Evolution of scapula size and shape in didelphid marsupials (Didelphimorphia: Didelphidae). Evolution 63: 2438-2456.

Beveridge, I., N. B. Chilton, P. M. Johnson, L. R. Smales, R. Speare, AND D. M. SPRATt. 1998. Helminth paraasite communities of kangaroos and wallabies (Macropus spp. and Wallabia bicolor) from north and central Queensland Australian Journal of Zoology 46: 473-495.

Brooks, D. R., And D. A. McLennan. 2002. The nature of diversity: An evolutionary voyage of discovery. University of Chicago Press, Chicago, Illinois, $668 \mathrm{p}$.

Bush, A. O., K. D. Lafferty, J. M. Lotz, and A. W. Shostak. 1997. Parasitology meets ecology on its own terms: Margolis et al. revisited. Journal of Parasitology 83: 575-583.

Cáceres, N. C., I. R. Ghizoni, and M. E. Graipel. 2002. Diet of two marsupials, Lutreolina crassicaudata and Micoureus demerarae, in a coastal Atlantic Forest island of Brazil. Mammalia 66: 331-339.

Cañeda-Guzmán, I. C. 1997. Parásitos de tres especies de marsupiales de la estación "Los Tuxtlas" y algunas zonas cercanas, Veracruz, México. Universidad Nacional Autónoma de México, México City, D.F., México, 193 p.

Carvalho, F. M. V., F. A. S. Fernandez, and J. L. Nessimian. 2005. Food habits of sympatric opossums coexisting in small Atlantic Forest fragments in Brazil. Mammalian Biology 70: 366-375.

Castro-Arellano, I., H. Zarza, and R. A. Medellín. 2000. Philander opossum. Mammalian Species 638: 1-8.

Choudury, A. 2001. Sturgeons (Chondrostei: Acipenseridae) and their metazoan parasites: Patterns and processes in historical biogeography. Journal of Biogeography 28: 1411-1439.

, AND T. A. Dick. 2000. Richness and diversity of helminth communities in tropical freshwater fishes: Empirical evidence. Journal of Biogeography 27: 935-956.

Combes, C. 1991. Evolution of parasite life cycles. In Parasite-host associations. Coexistence or conflict?, C. A. Toft, A. Aeschlimann, and L. Bolis (eds.). Oxford University Press, Oxford, U.K., p. 62 82.

Cordell, R. L. 1974. Helminth parasites of the Virginia opossum, Didelphis marsupialis virginiana, in Southern Illinois. M.S. Thesis. Southern Illinois University, Carbondale, $55 \mathrm{p}$.

Cunha, A. A., And M. V. Vieira. 2002. Support diameter, incline, and vertical movements of four didelphid marsupials in the Atlantic forest of Brazil. Journal of Zoology 258: 419-426.

Dogiel, V. A. 1964. General parasitology. Oliver \& Boyd Ltd., Edinburgh, U.K., 516 p.

Ellis, R. D., O. J. Pung, and D. J. Richardson. 1999. Site selection by intestinal helminths of the Virginia opossum (Didelphis virginiana). Journal of Parasitology 85: 1-5.

Felsenstein, J. 1985. Phylogenies and the comparative method. American Naturalist 125: 1-15.

. 2009. PHYLIP" Phylogeny inference package. Software distributed by the author, Department of genomic Sciences, University of Washington, Seattle, Seattle, Washington.

Fleming, T. H. 1972. Aspects of the population dynamics of three species of opossums in the Panama Canal Zone. Journal of Mammalogy 53: 619-623.

Gardner, A. L. 2007. Mammals of South America. University of Chicago Press, Chicago, Illinois, $669 \mathrm{p}$

Gentile, R., R. Finotti, V. Rademaker, and R. Cerqueira. 2004. Population dynamics of four marsupials and its relation to resource production in the Atlantic forest in southeastern Brazil. Mammalia 68: $109-119$.

González, M. T., C. Barrientos, and C. A. Moreno. 2006. Biogeographical patterns in endoparasite communities of a marine fish (Sebastes capensis Gmelin) with extended range in the Southern Hemisphere. Journal of Biogeography 33: 1086-1095.

Janovy, JR, J., R. E. Clopton, and T. J. Percival. 1992. The roles of ecological and evolutionary influences in providing structure to parasite species assemblages. Journal of Parasitology 78: 630-640.

Jiménez-Ruiz, F. A., L. García-Prieto, and G. Pérez-Ponce de León. 2002. Helminth infracommunity structure of the sympatric garter snakes Thamnophis eques and Thamnophis melanogaster from the Mesa Central of Mexico. Journal of Parasitology 88: 454 460.

JuLIEN-LAFERRIÈRE, D. 1991. Organisation du peuplement de marsupiaux en Guyane Française. La Terre et la Vie Revue D’Ecologie 46: 125-144. 
, And M. Atramentowicz. 1990. Feeding and reproduction of three didelphid marsupials in two Neotropical forests (French Guiana). Biotropica 22: 404-415.

Krasnov, B. R., G. I. Shenbrot, D. Mouillot, I. S. Khokhlova, and R. Poulin. 2005. Spatial variation in species diversity and composition of flea assemblages in small mammalian hosts: Geographical distance or faunal similarity? Journal of Biogeography 32: 633644.

McManus, J. J. 1974. Didelphis virginiana. Mammalian Species 40: 1-6.

Meyer-Lucht, Y., C. Otten, T. Puttker, R. Pardini, J. P. Metzger, and S. Sommer. 2010. Variety matters: Adaptive genetic diversity and parasite load in two mouse opossums from the Brazilian Atlantic forest. Conservation Genetics 11: 2001-2013.

Monet-Mendoza, A., D. Osorio-Sarabia, and L. García-Prieto. 2005. Helminths of the Virginia opossum Didelphis virginiana (Mammalia: Didelphidae) in Mexico. Journal of Parasitology 91: 213-219.

Navone, G. T., And D. M. Suriano. 1992. Species composition and seasonal dynamics of the helminth community parasitizing Didelphis albiventris (Marsupialia: Didelphidae) in savannas of central Argentina. Ecología Austral 2: 95-1000.

Nelson, G., And N. I. Platnick. 1981. Systematics and biogeography: Cladistics and vicariance. Columbia University Press, New York, New York, 567 p.

Pavlovsky, E. N. 1966. Natural nidality of transmissible diseases, with special reference to the landscape epidemiology of zooanthroponoses University of Illinois Press, Urbana, $261 \mathrm{p}$.

Pence, D. B. 1990. Helminth community of mammalian hosts: Concepts at the infracommunity, component community and compound community levels. In Parasite communities: Patterns and processes,
G. W. Esch, A. O. Bush, and J. M. Aho (eds.). Chapman and Hall, New York, New York, p. 233-260.

Poulin, R. 2003. The decay of similarity with geographical distance in parasite communities of vertebrate hosts. Journal of Biogeography 30: 1609-1615. . 2007. Evolutionary ecology of parasites, 2nd ed. Princeton University Press, Princeton, New Jersey, 332 p.

, AND T. A. Dick. 2007. Spatial variation in population density across the geographical range in helminth parasites of yellow perch Perca flavescens. Ecography 30: 629-636.

Pritchard, M. H., and G. O. W. Kruse. 1982. The collection and preservation of animal parasites. University of Nebraska Press, Lincoln, 141 p.

Richardson, D. J., AND J. D. CAMPO. 2005. Gastrointestinal helminths of the Virginia opossum (Didelphis virginiana) in south-central Connecticut, USA. Comparative Parasitology 72: 183-185.

SAS Institute InC. 2009. The data analysis for this paper was generated using SAS software. SAS Institute Inc., Cary, North Carolina.

Silva, M. G. Q. D., And H. M. A. Costa. 1999. Helminths of white-bellied opossum from Brazil. Journal of Wildlife Disseases 35: 371-374.

SwofFord, D. L. 2003. PAUP*: Phylogenetic analysis using parsimony (*and other methods) Sinauer Associates, Sunderland, Massachusetts.

Voss, R. S., AND S. A. JAnsA. 2009. Phylogenetic relationships and classification of didelphid marsupials, and extant radiation of New World metatherian mammals. Bulletin of the American Museum of Natural History 322: 1-177.

WELCH, B. L. 1947. The generalization of 'Student's' problem when several different population variances are involved. Biometrika 34: 28-35.

Wilson, D. E., And D. M. Reeder. 2005. Mammal species of the world: A taxonomic and geographic reference, 3 rd ed. Johns Hopkins University Press, Baltimore, Maryland, 2142 p. 